Dossiê: Religião e globalização

\title{
Globalização e religião \\ Efeitos do pluralismo global no campo religioso contemporâneo
}

\section{Globalization and religion}

Effects of the global pluralism on the contemporary religious sphere

Airton Luiz Jungblut*

Resumo: Neste artigo discute-se alguns dos efeitos da globalização sobre a religião. São abordados as relações entre globalização e tradição e o efeito destradicionalizante deste processo ao favorecer a pluralização religiosa e, consequentemente, uma grande autonomia identitária dos indivíduos em busca de bens religiosos. Para tanto, são analisados dois casos reveladores de dinâmicas distintas frente a esses processos todos.

Palavras-chave: Globalização e religião. Pluralização religiosa. Mercado religioso. Autonomia identitária.

Abstract: In this article are discussed some of the effects of the globalization on religion, such as the relation between globalization and tradition, and the detraditionalizationing effect that globalization has by promoting religious pluralization and, consequently, leading to an autonomy of identities of those individuals who search for religious goods. For that, I analyze two cases with distinct features regarding all these processes.

Keywords: Globalization and religion. Religious pluralization. Religious market. Autonomy of identities.

* Doutor em Antropologia Social pela Universidade Federal do Rio Grande do Sul (Ufrgs, Porto Alegre, RS, Brasil), professor no PPG em Ciências Sociais da Pucrs em Porto Alegre, RS, Brasil)<jungblut.ez@terra.com.br>.

\begin{tabular}{|c|c|c|c|c|c|}
\hline Civitas & Porto Alegre & v. 14 & n. 3 & p. 419-436 & set.-dez. 2014 \\
\hline
\end{tabular}

A matéria publicada neste periódico é licenciada sob forma de uma 


\section{Introdução}

Já faz tempo que a religião e o que se tem chamado de globalização aparecem como temas facilmente associáveis. Se tomarmos globalização em uma de suas definições mais correntes, qual seja, como um processo histórico amplo e complexo de difusão cultural multidirecional em escala planetária, é impossível não tropeçar nos exemplos disponíveis no campo religioso para ilustrar as lógicas difusionistas que animam tal fenômeno. O sucesso obtido por muitas tradições religiosas em se difundir mundialmente surge naturalmente, a evidenciar uma tendência muito visivelmente prematura na história da humanidade, a de que ocorram influxos culturais -simétricos ou assimétricos- entre sociedades distintas. Influxos esses que se tornam cada vez mais acentuados a partir do momento em que começam a surgir as grandes civilizações. Não é por outra razão que os processos de difusão de religiões "mundiais" como o judaísmo, o cristianismo, o islamismo e o budismo ilustram exuberantemente as lógicas da globalização. ${ }^{1}$

Ao se pretender a análise da religião atual de mãos dadas com as questões suscitadas pela globalização vivida na contemporaneidade, é imperativo que se reconheça as novas maneiras utilizadas pelas religiões atuais, cada vez mais pluralizadas em inúmeras modalidades, para difundirem-se e buscarem, com maior ou menor intensidade, a mundialização. De antemão é necessário reconhecer que o modelo mais verticalizado de difusão globalizante, $d o$ centro para a periferia, ainda hegemônico no campo religioso, cede espaço a modalidades mais horizontalizadas de difusão, ou, como observa José Jorge de Carvalho (2001, p. 443), a uma globalização "que é negociada horizontalmente não a partir de centros de poder político e econômico, mas de um ponto remoto, embora radicalmente não-periférico".

Uma das coisas que mais fica evidente nesse processo de horizontalização da globalização da religião é o ganho de autonomia identitária dos indivíduos frente às "tradições" que sustentam muitas das modalidades religiosas existentes na atualidade. As religiões -e mesmo as religiosidades mais difusas e desinstitucionalizadas do mundo moderno-necessitam, em maior ou menor escala, algum ancoramento em tradições com alguma profundidade histórica. É preciso ter em mente, portanto, o processo de destradicionalização que é desencadeado pela globalização e que afeta o campo religioso mundial. Atentemos, portanto, primeiramente, para as lógicas desse processo.

Otávio Velho (2001, p. 107) sugere que o "apelo para o transcendente", que geralmente caracteriza a religião, tem legitimado "o desrespeito às fronteiras, constituindo a história das chamadas "religiões mundiais"'. 


\section{Destradicionalização e globalização}

Segundo Giddens, "tradição" funciona basicamente como uma "orientação para o passado, de tal forma que o passado tem uma pesada influência ou, mais precisamente, é constituído para ter uma pesada influência sobre o presente". E, prossegue o autor, "a tradição também diz respeito ao futuro pois as práticas estabelecidas são utilizadas como uma maneira de se organizar o futuro" (Giddens, 1997, p. 80). Dessa forma, é fundamental para a existência da tradição a "repetição" ou "rotinização da conduta cotidiana" (Giddens, 1997, p. 90) como "maneira de ficar no 'único mundo que conhecemos', um meio de evitar a exposição a valores ["ou a maneiras de ser"] 'estranhos"” (Giddens, 1997, p. 92).

A repetição ou rotinização como forma de perpetuar a tradição passa, segundo Giddens, na modernidade, gradativamente a não mais ocorrer como outrora, já que "torna-se vazia, a menos que esteja ajustada aos processos da reflexividade institucional" (Giddens, 1997, p. 90) e, fora isso, prossegue o autor, não há na atualidade "lógica -autenticidade moral- em fazer hoje o que fizemos ontem; mas estas coisas são a verdadeira essência da tradição" (Giddens, 1997, p. 90-91).

Em sociedades que passaram por um processo de destradicionalização ocorre então que o indivíduo não tem "outra escolha senão decidir como ser e como agir" (Giddens, 1997, p. 94) já que, como sugere Giddens, a tradição não mais lhe constrange a repetir o passado ou, parafraseando Bauman (1998, p. 113), já que o passado está proibido de se relacionar com o presente. Tendo que decidir "como ser e como agir", o indivíduo torna-se um ativo "escolhedor", o que, por consequência, lhe fortalece ou the fornece a autonomia: "a escolha ativa certamente produz - ou é - a autonomia" (Giddens, 1997, p. 94).

Mas, como nos mostra Giddens, há uma série de relações entre destradicionalização e outros processos sociais, alguns dos quais só se tornaram mais visíveis nos últimos anos. Algumas destas relações revelam características interessantes sobre a agência individual atual relacionadas à religião. É o caso, por exemplo, da relação entre destradicionalização e globalização.

Giddens faz-nos ver como a globalização tem um papel muito importante na forma como ocorreu o processo de destradicionalização:

Até uma época relativamente recente, grande parte do mundo permaneceu em um estado quase segmentário, em que ainda persistiam numerosos grandes enclaves do tradicionalismo. Nessas áreas -e também em algumas regiões e contextos dos países 
industrialmente desenvolvidos-, a comunidade local continuou a ser forte. Nas últimas décadas, particularmente influenciado pelo desenvolvimento da comunicação eletrônica global instantânea, estas circunstâncias se alteraram de maneira radical. Um mundo em que ninguém é 'forasteiro', é um mundo em que as tradições preexistentes não podem evitar o contato, não somente com os outros - mas também com muitos- modos de vida alternativos. Justamente por isso, é um mundo em que o 'outro' não pode mais ser tratado como inerte. A questão não é somente que o outro 'responda', mas que a interrogação mútua seja possível” (Giddens, 1997, p. 119).

Numa linha de análise semelhante a esta, Alain Finkielkraut (1998, p. 115-116) oferece uma interessante imagem para o indivíduo que surge deste processo: a "mundialização do eu" como a imagem que designa aquele "turista de si mesmo e turista do outro, [que] percorre, à guisa de mundo, um imenso parque de diversões, um museu interminável em que a identidade e a diferença se oferecem igualmente ao seu olhar discricionário".

Segundo Francisco Rüdiger (1996, p. 15), é esse estado de coisas, vigente na sociedade contemporânea, que torna os indivíduos mais autônomos em relação às "representações coletivas que outrora lhe engessavam a identidade e prescreviam-lhe um conceito com pretensão de validade para toda a vida".

Anthony Giddens é quem talvez ofereça o modelo mais bem acabado para compreensão das lógicas que orientam os exercícios internos que o eu moderno tem que realizar para adaptar-se e deslocar-se nas sociedades ocidentalizadas dos tempos atuais. Sua noção de "reflexividade do eu" como um projeto da modernidade "ao mesmo tempo emancipatório e constrangedor" (Giddens, 1993, p. 87) para o indivíduo, sintetiza de forma bastante elucidadora as ambiguidades a que estão sujeitas as pessoas na atualidade diante dos dilemas de terem que exercitar uma liberdade de opções que se mostra simultaneamente recompensadora em sua natureza democrática e opressora em sua natureza compulsória. Para Giddens (1993, p. 87), a partir da vigência deste projeto, as opções, as escolhas individuais, desde as mais corriqueiras do cotidiano até as mais determinantes para a trajetória dos indivíduos, passam a ter que ser pensadas:

[...] em termos de uma sociedade em que a tradição tem sido mais abandonada do que jamais foi, e em que o projeto reflexivo do eu assume correspondentemente uma importância especial. Quando grandes áreas da vida de uma pessoa não são mais compostas por padrões e hábitos preexistentes, o indivíduo é continuamente obrigado a negociar opções de estilo de vida. Além disso -e isto é crucial-, tais escolhas não são apenas aspectos 'externos' ou 
marginais das atitudes do indivíduo, mas definem quem o indivíduo 'é'. Em outras palavras, as escolhas de estilo de vida constituem a narrativa reflexiva do eu.

Por conta, em grande parte, dos efeitos destradicionalizantes da globalização, o eu da atualidade é, portanto, se tomarmos como aceitável o que nos diz Giddens, alguém dotado de auto-reflexão, de autodeterminação e que não se vê mais constrangido a adotar e a seguir as diretrizes armazenadas na tradição.

Como se encontram mais libertos das tradições, embora constantemente constrangidos a se posicionar identitariamente, o efeito não poderia ser outro que não a explosão da "diferença", o pluralismo identitário que afeta todas as esferas da cultura aí incluída a religião. Mas se há processos pelos quais novas identidades-diferenças são criadas à margem de padrões institucionais mais fortes e alimentadas, moldadas e/ou abandonadas a partir de comportamentos até então inusitados, há também outros processos pelos quais diferenças tradicionais institucionalizadas enfrentam dilemas da mesma forma inusitados.

Há, em primeiro lugar, mais visivelmente um movimento no sentido de uma certa desidentificação generalizada para com algumas das diferenças tradicionais que dissolviam o eu em agrupamentos mais amplos ou, como, diz Rüdiger (1996, p. 222), há "uma relutância em aceitar as características que tradicionalmente conceituavam o eu (sexo, raça, credo etc.)".

Mas há também aquilo que Antônio F. Pierucci chama de "diferencialismo disseminante", entendido como uma explosão da pluralização, como uma "proliferação das diferenças" e que, em seu movimento mais interessante, age no sentido de pluralizar internamente as próprias diferenças historicamente estáveis.

O estado atual é de pluralização radical. Hoje tem muita gente tentando pensar a ação 'simultânea, divergente e desigual' das diferenças coletivas se cruzando, se recruzando, se entrecruzando, novas diferenças sendo interpeladas à existência política no discurso dos movimentos, querendo ser discursivamente representadas na sua pretensão de reconhecimento público, demandando portanto existência política, cidadania, alteridades outras sobrepondo-se umas às outras, para reforço ou achatamento de antigas identificações, todo um carnaval de diferenças encavalando-se e penetrando-se mutuamente num mesmo sujeito individual [...]: intersecções. Intersecções num mesmo indivíduo de pertencimentos múltiplos, múltiplas lealdades, múltiplas posições ou 'posicionalidades', múltiplas identificações e identidades grupais, múltiplos 
'reposicionamentos' além do mais. E a identidade individual, não seria múltipla também ela? Não será? Não seremos, nós outros, identidades múltiplas em subjetividades múltiplas? (Pierucci, 1999, p. 142-143).

Alain Touraine (1998, p. 67) parece estar pensando num quadro como este quando nos alerta que, na atualidade, em relação a definições identitárias a "racionalidade não é mais objetiva, substancial, mas formal, instrumental e, portanto, situa-se no plano dos meios e não dos fins" e, por assim ser, "ela pode se combinar com finalidades culturais ou psicológicas em cada ator individual". O autor explica:

Não se pode ser ao mesmo tempo cristão e ateu ou muçulmano, mas nada impede ser ao mesmo tempo especialista em informática ou vendedor e cristão, muçulmano ou ateu. É preciso ainda que estes dois universos de comportamento não se justaponham, permanecendo estranhos um ao outro, e que seja, pois, definido um princípio que permita combiná-los. Não vejo outra possibilidade além da vontade e do esforço de cada ator, individual ou coletivo, para construir sua individuação, ou seja, para dar um sentido geral ao conjunto das situações, das interações e das condutas que formam a sua existência e que, portanto, a transformam numa experiência (Touraine, 1998, p. 67-68).

Esta fragmentação identitária, tão evidente na atualidade em que, parafraseando Ulrich Beck (1997, p. 19), “o eu (self) não é mais o eu inequívoco, mas se tornou fragmentado em discursos fragmentados do eu", leva então o indivíduo a fazer seu próprio "cocktail individualista" (Lipovestky, 1983, p. 111), mistura eclética, sincrética, aberta, efêmera, de traços identitários em que o eu autonomiza-se em relação ao social e aos grandes sistemas de significados.

Percebe-se, ao final, que a globalização, atuando como força destradicionalizante, destrava as amarras que tornam os indivíduos demasiadamente atrelados a identificações bancadas por tradições fortes como, muito visivelmente, ocorre no campo religioso. Como consequência disso, tanto aquelas religiões institucionalizadas, que são bancadas por tradições fortes, como as novas modalidades religiosas contemporâneas, menos tradicionalmente "profundas", mas com algum grau de institucionalização, ao se deparem com esse indivíduo autonomizado em relação à tradição, necessitam operar processos de reflexividade institucional, necessitam reposicionarem-se identitariamente o tempo todo. 
O termo destradicionalização, por sua vez, também tem sido utilizado para abordar as transformações pelas quais passa a religião (Velho, 1997; Fry, 1998; D'Andrea, 1996; Pedde, 1999) contemporânea a partir, principalmente, da erosão provocada pela globalização. Conjuntamente, também tem havido o emprego de outros neologismos para tratar de aspectos mais precisos desse processo e que atingem especialmente algumas tradições religiosas específicas, como, por exemplo, "desteologização" para nomear aquilo que estaria ocorrendo em muitas das formas de pentecostalismo, quando se passa a valorizar muito mais as experiências extáticas e o pragmatismo do que os argumentos teológicos (Velho, 1997, p. 56).

Como se viu até aqui, há uma intrincada relação entre globalização, destradicionalização, autonomização individual e práticas identitárias. A globalização, reduzindo as distâncias espaço-temporais, produz o avizinhamento dos grupos humanos, forçando-os a interações e intercâmbios culturais inegavelmente destradicionalizantes. O pluralismo cultural acentuado, decorrente dessa situação, favorece, por sua vez, a autonomia dos indivíduos que necessitam, frequentemente, posicionar-se em relação a muitos itens identitários (estéticos, religiosos, políticos etc.) disponibilizados através dessa pluralização. Em função disso, instituições e indivíduos que celebram os vínculos com tradições fortes, como as religiões, passam a ter que administrar "reflexivamente", o tempo inteiro, o conjunto de sinais diacríticos que compõem suas identidades. Passemos agora, a uma análise mais focalizada da questão identitária por trás dessa destradicionalização operada pela globalização.

\section{Identidade e globalização: o caso da Igreja Universal do Reino de Deus}

Quando se fala em identidades, em contextos de globalização, é quase impossível não se recorrer aos aportes teóricos desenvolvidos por antropólogos que estudaram a etnicidade em contextos interéticos como aqueles desencadeados pela globalização. ${ }^{2}$ São alguns dos autores desenvolvedores desses aportes que, já há algumas décadas, construíram a conviç̧ão nas Ciências Sociais de que só faz sentido pensar em identidade étnica como uma categoria "relacional". Eles defendem que a construção e ostentação de

\footnotetext{
2 Segundo Luiz F. D. Duarte (1986, p. 70), “[o] uso da categoria de identidade [...] perpassa o discurso da antropologia de maneira ao mesmo tempo viva e encoberta, central e implícita, ubíqua e ambígua. Sua utilização mais evidente tem ocorrido em espaços segmentados como os da 'identidade étnica', da 'identidade nacional' e da 'identidade de gênero' encontrando sobretudo no tocante à 'identidade étnica' uma sofisticação bastante notável”.
} 
uma identidade só ocorre quando o grupo que a detém está imerso em um contexto interétnico de interações. A identidade étnica é, assim, uma maneira de demarcar e administrar uma diferença entre o "nós" e os "outros" existentes no social envolvente, possuindo, portanto, uma função "organizacional" (Barth, 1998). Ela é construída a partir de uma seleção sempre cambiante, de acordo com o momento e o propósito, de traços diacríticos retirados da tradição do grupo e encenados performaticamente. Nessa perspectiva, a "tradição cultural" de um grupo seria, tão somente, parafraseando Manuela Carneiro da Cunha (1987, p. 88), o "porão", o "reservatório" de onde se retira, quando se faz necessário, os "traços culturais isolados do todo que servirão, essencialmente, como sinais diacríticos para uma identificação étnica". Ora, como religião e etnicidade podem ser consideradas imersas em tradições fortes que frequentemente andam de braços dados, se retroalimentando uma da outra, muito do que vale para identidades étnicas também vale para identidades religiosas. Desta forma, sigamos com a apropriação desse aporte para a análise de questões que interconectam globalização, identidade e religião.

Tomemos o caso da Igreja Universal do Reino de Deus (Iurd), uma instituição religiosa brasileira inspirada em doutrinas pentecostais norteamericanas que, depois de grande expansão local, iniciou processo de expansão para outros países, mostrando-se, portanto um caso exemplar para o que estamos a analisar aqui.

A Iurd, ponta de lança do crescimento evangélico no Brasil nas últimas décadas, ostenta uma identidade que é constantemente -e talvez mais do que qualquer outro grupo religioso no país- posta em contrataste por seus agentes com as identidades de outros grupos religiosos. Este exercício contínuo e, até certo ponto, agressivo, de ostentação da sua identidade pela detratacão das identidades alheias, pode, num certo sentido, ser explicado pelo caráter nitidamente concorrencial e expansionista desta igreja. Sua estratégia de, insistentemente, desqualificar os concorrentes para com isso conquistar o maior número possível de fiéis, torna, portanto, a expressão de sua identidade um exercício fundamentalmente contrastivo. Opera neste caso aquilo que Roberto Cardoso de Oliveira chama de "identidade contrastiva":

A identidade contrastiva parece se constituir na essência da identidade étnica, i. e., à base da qual esta se define. Implica a afirmação do nós diante dos outros. Quando uma pessoa ou um grupo se afirmam como tais, o fazem como meio de diferenciação em relação a alguma pessoa ou grupo com que se defrontam. É uma identidade que surge por oposição. Ela não se afirma isoladamente. No caso da identidade étnica, ela se afirma 'negando' a outra identidade, 'etnocentricamente' por ela visualizada (Oliveira, 1976, p. 5-6). 
Como se dá esse exercício no caso dessa igreja? Várias são as possibilidades de que um grupo dispõe para afirmar sua identidade, negando, etnocentricamente, as identidades dos "outros". Em determinadas modalidades de cultos afro-brasileiros, por exemplo, é comum que um determinado grupo advogue para si maior correspondência com modelos africanos, enquanto para os outros grupos concorrentes é atribuída uma negligência para com a manutenção destes modelos. Neste caso, contrapõe-se uma manutenção correta ("pura") de crenças e procedimentos rituais a uma manutenção incorreta ("contaminada", sincrética) dos símbolos em jogo. No caso da Iurd, é possível notar que o mencionado exercício de contrastividade entre as identidades que representam o "nós" e os "outros" tem, como elemento simbólico fundamental, as representações e imagens do diabo. A imagem desse ente maligno e seus demônios auxiliares é invocada em quase todos os momentos em que os agentes dessa igreja referem-se aos concorrentes. A intenção é clara: associando os concorrentes ao diabo e denunciando a periculosidade de tal associação, fica mais fácil chamar para si a exclusividade da associação com o ente benigno que o combate, Deus. Esta disposição polarizada, Deus -nósversus o diabo -os outros-é frequentemente manifestada nas palavras de seus pastores. Um trecho de uma das obras do Bispo Macedo, o líder máximo desta igreja, é também revelador:

Tanto no alto espiritismo como no baixo, seja qual for o rótulo usado, o consulente é encaminhado sorrateiramente até envolver-se totalmente com o mundo dos espíritos. Umbanda, Quimbanda, Candomblé, Kardecismo, Bezerra de Menezes, Yokanan, Esoterismo etc., são apenas nomes de seitas e filosofias usadas pelos demônios para se apoderarem das pessoas que a eles recorrem, ora buscando ajuda, ora se envolvendo por mera curiosidade (Macedo, 1987).

Pode-se, contudo, observar que as associações que a Iurd faz entre as religiões concorrentes e o diabo obedece a uma classificação diferenciada para cada caso. Com relação às religiões afro-brasileiras, a associação é percebida como direta, pois os adeptos de tais cultos são acusados de estarem lidando com o diabo, de forma explícita e consciente. No caso do catolicismo e do espiritismo, sugere-se que seus adeptos estão praticando uma religião considerada errada. Seus fiéis são, portanto, tidos como enganados pelo diabo e, em virtude disso, associados a ele. Já no caso das religiões evangélicas e pentecostais, reconhece-se que seus seguidores têm consciência da ação maléfica do diabo no mundo, mas esse reconhecimento, segundo a 
ótica dos membros da Iurd, não é o suficiente, uma vez que se recusam a combatê-lo ferrenhamente. Este fato serve para colocá-las sob suspeita de estarem associadas ao diabo, mesmo que inconscientemente.

As imagens e representações acerca do diabo são, portanto, altamente operacionais no exercício que os membros da Iurd fazem para construir sua identidade religiosa, a partir das identidades que atribuem aos grupos religiosos concorrentes. Interessante é notar que o "nós somos" da Iurd apoia-se mais na oposição ao diabo e seus aliados (as outras igrejas e religiões) do que nas associações com Deus, associações essas menos presentes nos discurso dessa igreja.

O elemento simbólico que acaba de ser analisado é, sem dúvida, o mais importante no exercício de construção da identidade da Iurd. Há, no entanto, outros aspectos importantes a serem observados. Nota-se que pastores e obreiros dessa igreja demonstram reticência quando provocados a se manifestar sobre temas teológicos mais aprofundados. Geralmente, quando inquiridos sobre questões doutrinárias que exijam maior conhecimento teológico, costumam advertir que o mais importante não é procurar conhecer Deus, mas, sim, crer na sua existência e poder, e isso com a maior fé que se puder demonstrar.

Muito mais do que revelar um certo despreparo destes agentes para com questões teológicas mais elaboradas, essa negligência informa sobre uma imagem que a Iurd ostenta e opõe a certos concorrentes seus. Trata-se da oposição "fé versus sabedoria", em que a primeira é valorizada em detrimento da segunda. Esta oposição serve para estabelecer que o "nós" da Iurd está verdadeiramente comprometido com o exercício da fé -algo propagado por ela como positivo- enquanto alguns dos "outros" externos comprometem-se mais com o culto à sabedoria, que é vista como potencialmente inibidora da fé, portanto, negativa. Isso fica bem evidente quando o bispo Macedo afirma, em seu livro A libertação da teologia, o seguinte:

A primeira coisa que o homem deve fazer para compreender a Deus é crer. Por isso, insistimos em dizer que fé é uma questão de prática, e nunca de estudos; ela só deve ser vivida, e não mentalizada. Experimente o leitor fazer isso, e viva em uma nova dimensão, na presença de Deus. [...] Infelizmente, existe hoje também dentro das igrejas uma idolatria acentuada da sabedoria. Os livros que falam acerca da Bíblia são mais lidos do que a própria Bíblia; os pregadores falam 80 ou mais por cento, em suas pregações, dos problemas sociais, de política, de filosofia ou de si mesmos e quase nada, de Deus ou de Cristo (Macedo, s. d.). 
A oposição fé versus sabedoria serve, como se pode perceber, para fornecer à identidade da Iurd mais um contraste operacional entre o que deve ser tomado como característica sua -a fé- e o que deve ser tomado como característica de outras igrejas - a fé inibida pela sabedoria. Essa contrastividade é exercida principalmente nas acusações que são dirigidas à Igreja Católica e às igrejas evangélicas mais tradicionais e faz parte do repertório de acusações que seus agentes (pastores e obreiros) dirigem a esses concorrentes.

A Iurd, como se percebe, disputa fiéis em várias frentes e contrapõe para cada caso facetas diferentes da sua identidade. Como não poderia deixar de ser, age também no território pentecostal. Ali, entre os seus semelhantes, um dos traços diferenciadores enfatizados é a tolerância ou ausência de vigilância para com os comportamentos cotidianos de seus adeptos, ou seja, a Iurd, é bastante liberal, em se tratando de "usos e costumes", em oposição ao comportamento ascético e sectário das concorrentes. É claro que alguns comportamentos, tais como homossexualismo, alcoolismo, uso de drogas etc., são combatidos pela Iurd por serem interpretados como consequências de obras demoníacas, mas, contrariamente a outras denominações pentecostais mais tradicionais, não é feita uma cobrança mais firme sobre as atitudes dos fiéis. A este ascetismo, encontrado em muitas igrejas pentecostais, a Iurd contrapõe uma visível liberalidade para com os comportamentos profanos. Tem-se, assim, um pentecostalismo mais liberal do que aquele normalmente encontrado neste território, configurando-se, portanto, em mais um sinal contrastivo.

A essa contrastividade identitária desenvolvida e exercitada pela Iurd no Brasil se somam outras estratégias distintas quando esse grupo busca expansão no exterior. Em a Igreja Universal do Reino de Deus: os novos conquistadores da fé, obra organizada por Oro, Corten e Dozon (2003), estão descritos contextos onde a Iurd é obrigada a antagonizar identitariamente com outras forças religiosas: o culto aos mortos no Japão (Freston, 2003, p. 219); a idolatria hinduísta na Índia (idem, p. 223); os curandeiros, o "mal de ojo" e os feitiços na Argentina (Semán, 2003, p. 74); o culto à Virgem de Guadalupe no México (tida como "uma imagem demoníaca coberta de ouro" - Doran, 2003, p. 99); as testemunhas de Jeová, a Nova Era e religiões orientalizadas em Portugal (Mafra, 2003, p. 173).

Por tudo isso que foi colocado, é impossível não reconhecer que a Iurd tem características empresariais e expansionistas. Não se pode deixar de levar em consideração a avidez que essa igreja demonstra em se tornar cada vez maior, disputando abertamente fiéis com outras igrejas e/ou religiões. $\mathrm{O}$ arranjo feito em torno de sua identidade, portanto, obedece a uma "estratégia simbólica", em que os símbolos ou traços identitários são escolhidos, ajustados 
e manipulados visando a atender aos seus interesses de expansão como grupo proselitista. Situada num universo de diversidade religiosa, em que são muitas as agências a oferecer soluções mágico-religiosas para todos os tipos de demandas, a Iurd, como mais uma destas agências de fornecimento de soluções sobrenaturais, procura tornar-se a mais atraente possível para conquistar uma clientela cada vez maior. Seus interesses, portanto, traduzem-se na sua vontade de crescer e tornar-se poderosa num mercado de fé em constante expansão que obedece ao processo de "revitalização religiosa" que se assiste em grandes áreas da sociedade contemporânea.

Peter Berger (1985, p. 149-151), ao diagnosticar uma situação de disputa mercadológica entre as várias modalidades de religião existentes no Ocidente contemporâneo, nos faz perceber que os grupos religiosos são constrangidos, em razão da pressão que sofrem para obter bons resultados nesse mercado, a racionalizarem burocraticamente suas estruturas sociorreligiosas.

Em se tratando de tradições religiosas que remontam a séculos ou milênios, essas readaptações organizacionais são sempre mais demoradas e difíceis de ocorrerem em função do peso da tradição que sobre elas incide, constrangendo negativamente aqueles movimentos de renovação e readaptação exigidos pela contemporaneidade. Já nas organizações mais novas e melhor sintonizadas com as lógicas atuais, vê-se, normalmente, o contrário. Como ainda não se solidificaram plenamente em termos identitários, organizacionais, dogmáticos, litúrgicos etc., elas podem, mais facilmente, absorver aquelas transformações necessárias a um melhor desempenho mercadológico.

Tem-se hoje no meio evangélico brasileiro, por exemplo, formatos organizacionais que, discreta ou escancaradamente, vêm assumindo feições empresariais adequadas às exigências do mercado que, em nada, lembram as formas tradicionais de congregações religiosas. Tais mudanças aparecem expressas, inclusive, na própria terminologia elaborada no calor da hora para classificá-las, como "agências de cura divina" (Monteiro, 1979), "supermercados da fé” (Jardilino, 1994), "igrejas-empresas" (Pierucci, 1997), "holdings da fé" (Fonseca, 1997) etc. Fenômeno que se observa igualmente na "marketização do sagrado" (Campos, 1996), que acompanha, de modo emblemático, as transformações organizacionais que vêm se processando nesse movimento religioso.

A forma como a Iurd, engenhosamente, constrói sua identidade, sempre de olho nos rivais e no que se mostra eficaz no mercado religioso envolvente, mostra que o sucesso desse grupo não se deve ao acaso, à sorte, mas, sim, a uma eficiente racionalidade mercadológica, construída ao longo de sua trajetória. Também o estilo empresarial emprestado a seu governo eclesiástico e à hábil 
utilização das modernas tecnologias de comunicação de massa para atrair féis a seus templos atestam o profissionalismo das estratégias expansionistas adotadas por esse grupo. Com todo esse sucesso, não há exagero em se afirmar que o surgimento dessa igreja incendeia o mercado religioso brasileiro. Depois de uma gradual pluralização das modalidades religiosas brasileiras, iniciada a partir dos anos cinquenta do século 20, o advento da Iurd, no final dos anos setenta, transforma esse cenário pluralizante numa situação de mercado, onde, cada vez mais, se escancara a inevitabilidade da disputa aberta por fiéis.

Retomando alguns dos pontos desenvolvidos no início deste artigo, podese, agora, constatar que essa engenharia identitária da Iurd ocorre em sintonia com as lógicas destradicionalizantes desencadeadas pela globalização. Como efeito da globalização no campo religioso brasileiro há uma pluralização de suas modalidades que vai, paulatinamente, corroendo o monopólio católico sobre esse campo e, visto que isso faculta aos indivíduos um aumento considerável das opções identitárias religiosas, um "situação de mercado" vai se consolidando rapidamente. Algo próximo daquilo que Gordon Mathews (2002) designa "supermercado cultural global" instaura-se no campo religioso brasileiro, potencializando a níveis consideráveis a autonomia de escolha dos interessados por bens religiosos. Que tipo de religião se beneficia desse tipo situação? O crescimento espantoso da Iurd e de outras igrejas neopentecostais que copiaram suas estratégias expansionistas sugere que são aquelas que aceitam jogar abertamente segundo as lógicas do "supermercado cultural global", ou seja, que estão atentas às demandas dos "escolhedores". Tais grupos religiosos mostram-se então hábeis em realizar aqueles exercícios de "reflexividade institucional" de que fala Giddens, extraindo de forma bastante flexível e inventiva os sinais diacríticos da tradição à qual se vinculam (o pentecostalismo norte-americano), mesmo que sua a difusão de seus produtos identitários se dê de forma verticalizada.

\section{Difusão horizontalizada de bens religiosos em tempos de globalização}

A autonomia do sujeito frente a um mercado pluralizado de bens religiosos não favorece somente as modalidades religiosas com maior disponibilidade e expertise em atender a esse "cliente". Favorece, também, um tipo de religião completamente desinstitucionalizada, aquela em que o "cliente" é o criador e seguidor de sua própria religião. Essa religião do "faça você mesmo", em franca expansão e, inegavelmente, turbinada pela globalização, tem levado, conforme Danièle Herviu-Léger (2008, p. 156-157), a uma situação cada vez mais visível de "crença sem pertencimento" em que os indivíduos, ao 
aderirem à lógica da "bricolagem da fé", acabam por dispensar a "constituição de comunidades crentes reunidas em torno de uma fé comum".

Essa autonomia de se vincular livremente a uma determinada tradição sem dela participar, aliada ao poder de compor seus próprios sistemas religiosos de acordo com suas necessidades e preferências pessoais, é o que tem caracterizado o conjunto de crenças denominado "Movimento Nova Era". Essas, como demonstra Anthony D'Andrea (1996), ao serem produzidas e atualizadas por um ativo "reflexivismo individual", têm, quase que exclusivamente, no compósito produzido pelo indivíduo a única e efetiva - se é que se pode chamar assim - unidade doutrinal verificável e, mesmo assim, sempre de uma forma aberta e provisória. Nesse processo as tradições tendem a não ser percebidas pelos indivíduos como unidades indecomponíveis mas, sim, como espécies de depósitos de onde é possível retirar peças sem que se precise levar todo o kit completo. E não se trata somente de ver esse tipo de sujeito apenas vinculado à New Age ou a modalidades ditas pós-modernas de religião ou religiosidade. No próprio seio de igrejas tradicionais podemos observar esse fenômeno formando aquilo que D'Andrea (1996) chama de "novaerização" do pertencimento às religiões tradicionais. É possível, por exemplo, transitar pelas várias modalidades existentes no interior do universo evangélico sem que seja necessário estar formalmente vinculado a nenhum grupo ou doutrina específica. Rubem Amorese denomina o sujeito que assim age neste meio de "crente beija-flor" (Amorese, 1993, p. 91-94).

Pois é essa religião ou religiosidade desinstitucionalizada, produzida artesanalmente e ao sabor das preferências identitárias do indivíduo, que emerge como o que há de mais sintonizado com os ventos destradicionalizantes soprados pela globalização. O "eu mundializado" que circula pelos "supermercados culturais globais" em busca de vínculos identitários que o ancorem, ao menos momentaneamente, a algo consonante com sua trajetória biográfica, suas expectativas em relação ao transcendente, sua personalidade religiosa. Aqui, tem-se portanto uma reflexividade individual ao invés de "institucional", como no caso anterior. A forma de difusão por ser, quase sempre, desinstitucionalizada, ocorre de através de uma negociação individual e horizontalizada. Se há alguma ideia de "mercado" que seja útil neste caso é aquela que se refere às "negociações" individuais, o "mercado formiga" produzido por atores em busca de conteúdos e interlocuções que lhes auxiliem a adotar o melhor posicionamento identitário e que são, ou autovalidados, ou validados mutuamente em negociações com outros interlocutores colaboradores igualmente desvinculados de instituições tradicionais (HervieuLéger, 2008, p. 163). 


\section{Considerações finais}

A globalização, como se pode supor, indiscutivelmente afeta a religião de múltiplas formas além dessas inventariadas aqui. Não se pretendeu, evidentemente, no curto espaço deste artigo, o esgotamento analítico de todas as formas assumidas pelas modalidades religiosas existentes no planeta $\mathrm{e}$ que sofreram a ação da globalização. Os dois tipos de religião abordados aqui, contudo $-\mathrm{o}$ primeiro a partir da análise de um grupo específico e o segundo com uma descrição de uma tendência religiosa mais desinstitucionalizada- explicitam, esquematicamente, os dois caminhos possíveis para religiões ou religiosidades bastante afetadas pela pluralização provocada pela globalização.

No primeiro caso, a de uma religião tutelada por uma organização, vemos todo um exercício de "reflexividade institucional" sendo feito com grande atenção ao pluralismo religioso envolvente. Este, ao proporcionar o avizinhamento de diferentes modalidades religiosas provindas, por efeito de uma globalização cosmopolizante, de diversos lugares do planeta, acaba por turbinar o poder de escolha dos agentes sociais interessados em commodities religiosas. A reflexividade institucional desencadeada pelo grupo torna-se, portanto, a condição para o sucesso de um compósito identitário disponibilizado no mercado religioso. Assim, fica patente que o sucesso de uma organização religiosa como esta, nestes dias de ativa cosmopolitização, está diretamente relacionado à sua capacidade de bem realizar eficientes exercícios de reflexividade institucional.

No segundo caso, essa construção e manutenção de compósitos identitários de natureza religiosa não encontra-se sob a tutela de uma organização especializada, cabendo ao próprio indivíduo a tarefa de elaborála e gerenciá-la. Também aqui, a lhes determinar as condições de existência desta prática, faz-se sentir toda a intrincada cadeia de processos que une globalização, destradicionalização, pluralização, aumento da autonomia identitária etc. Nessa religião ou religiosidade desinsitucionalizada, "selfservice", artesanal e que dispensa o pertencimento congregacional, é a "reflexividade individual" que se faz necessária ao processo de posicionamento identitário do sujeito. É essa reflexividade, outrossim, o combustível que faz prosperar uma religiosidade muito sintonizada com as tendências culturais contemporâneas. Talvez a sua força esteja no fato de que ela é a realização objetiva de um antigo projeto secularizante da modernidade: a de que a religião só tivesse como refúgio inviolável os recônditos privados do interior do indivíduo. 


\section{Referências}

AMORESE, Rubem M. Icabode: da mente de Cristo à consciência moderna. São Paulo: Abba Press, 1993.

BARTH, Fredrik. Grupos étnicos e suas fronteiras. In: Philippe Poutignat; Jocelyne Streiff-Fenart (Orgs.). Teorias da etnicidade: seguido de grupos étnicos e suas fronteiras de Fredrik Barth. São Paulo: Fundação Editora da Unesp, 1998. p. 185-228.

BAUMAN, Zygmunt. O mal-estar da pós-modernidade. Rio de Janeiro: Zahar Ed., 1998.

BECK, Ulrich. A reinvenção da política: rumo a uma teoria da modernização reflexiva. In: Ulrich Beck; Antony Giddens; Scott Lasch (Orgs.). Modernidade reflexiva: política, tradição e estética na ordem social moderna. São Paulo: Unesp, 1997. p. 11-71.

BERGER, Peter Ludwig. O dossel sagrado: elementos para uma teoria sociológica da religião. São Paulo: Ed. Paulinas, 1985.

CAMPOS, Leonildo Silveira. Teatro, templo e mercado: uma análise da organização, rituais, marketing e eficácia comunicativa de um empreendimento neopentecostal Igreja Universal do Reino de Deus. São Bernardo do Campo, Imes. Tese (Doutorado em Ciências da Religião), 1996.

CARVALHO, José J. Globalização, tradições, simultaneidade de presenças. In: Cândido Mendes; Luiz E. Soares (Orgs.). Pluralismo cultural, identidade e globalização. Rio de Janeiro: Unesco, 2001. p. 431-479.

CUNHA, Manuela Carneiro da. Antropologia do Brasil: mito, história, etnicidade. São Paulo: Brasiliense, 1987.

D'ANDREA, Anthony A. F. O self perfeito e a nova era: individualismo e reflexividade em religiosidades pós-tradicionais. Dissertação (Mestrado) - Programa de PósGraduação em Sociologia do Iuperj. Rio de Janeiro, 1996.

DORAN, Marie-Christine. A Igreja Universal no México. In: Ari Pedro Oro; André Corten; Jean-Pierre Dozon (Orgs.). Igreja Universal do Reino de Deus: os novos conquistadores da fé. São Paulo: Paulinas, 2003. p. 93-99.

DUARTE, Luiz F. D. Classificação e valor na reflexão sobre identidade social. In: Ruth Cardoso (Org.). A aventura antropológica: teoria e pesquisa. Rio de Janeiro: Paz e Terra, 1986. p. 69-92.

FINKIELKRAUT, Alain. A humanidade perdida: ensaio sobre o século XX. São Paulo: Ática, 1998.

FONSECA, Alexandre Brasil. Evangélicos e mídia no Brasil. Rio de Janeiro, UFRJ. Dissertação (Mestrado em Sociologia), 1997.

FRESTON, Paul. A Igreja Universal na Ásia. In: Ari Pedro Oro; André Corten; Jean-Pierre Dozon (Orgs.). Igreja Universal do Reino de Deus: os novos conquistadores da fé. São Paulo: Paulinas, 2003. p. 197-229.

FRY, Peter. Religião e destradicionalização na África austral. VIII Jornadas sobre Alternativas Religiosas na América Latina. São Paulo, 1998. 
GIDDENS, Anthony. A transformação da intimidade: sexualidade, amor e erotismo nas sociedades modernas. São Paulo: Editora da Universidade Estadual Paulista, 1993.

GIDDENS, Anthony. A vida em uma sociedade pós-tradicional. In: Ulrich Beck; Antony Giddens; Scott Lasch (Orgs.). Modernidade reflexiva: política, tradição e estética na ordem social moderna. São Paulo: Unesp, 1997. p. 73-134.

HERVIEU-LÉGER, Danièle. O peregrino e o convertido: a religião em movimento. Petrópolis: Vozes, 2008.

JARDILINO, José Rubens Lima. Sindicato dos mágicos: as religiões do espírito de orientação protestante no Brasil. Congresso Internacional as Novas Religiões Missões e Missionários, Recife, 1994.

LIPOVETSKY, Gilles. A era do vazio. Lisboa: Gallimard, 1983.

MACEDO, Edir. A libertação da teologia. Rio de Janeiro: Universal Produções, s. d.

MACEDO, Edir. Orixás, caboclos e guias: deuses ou demônios. Rio de Janeiro: Universal Produções, 1987.

MAFRA, Clara. A Igreja Universal em Portugal. In: Ari Pedro Oro; André Corten; JeanPierre Dozon (Orgs.). Igreja Universal do Reino de Deus: os novos conquistadores da fé. São Paulo: Paulinas, 2003. p. 165-176.

MATHEWS, Gordon. Cultura global e identidade individual. Bauru: Edusc, 2002.

MONTEIRO, Duglas Teixeira. Igrejas, seitas e agências: aspectos de um ecumenismo popular. In: Edênio Valle (Org.). A cultura do povo. São Paulo: Cortez e Moraes, Educ, 1979. p. 81-111.

OLIVEIRA, Roberto C. de. Identidade, etnia e estrutura social. São Paulo: Pioneira Editora: 1976.

ORO, Ari Pedro; CORTEN, André; DOZON, Jean-Pierre (Orgs.). Igreja Universal do Reino de Deus: os novos conquistadores da fé. São Paulo: Paulinas, 2003.

PEDDE, Valdir. Destradicionalização: uma perspectiva para o entendimento do fenômeno carismático nas igrejas históricas. IX Congresso Brasileiro de Sociologia, Porto Alegre, 1999.

PIERUCCI, Antônio F. Ciladas da diferença. São Paulo: Ed. 34, 1999.

PIERUCCI, Antônio Flávio. Interesses religiosos dos sociólogos da religião. In: Ari Pedro Oro; Carlos A. Steil (Orgs.). Globalização e religião. Petrópolis: Vozes, 1997. p. 249-262.

RUDIGER, Francisco R. Literatura de autoajuda e individualismo: contribuição ao estudo da subjetividade na cultura de massa contemporânea. Porto Alegre: Ed. Ufrgs, 1996.

SEMAN, Pablo. A Igreja Universal na Argentina. In: Ari Pedro Oro; André Corten; Jean-Pierre Dozon (Orgs.). Igreja Universal do Reino de Deus: os novos conquistadores da fé. São Paulo: Paulinas, 2003. p. 69-78.

TOURAINE, Alain. Igualdade e diversidade: o sujeito democrático. São Paulo: Edusc, 1998. 
VELHO, Otávio Globalização: antropologia e religião. In: Ari Pedro Oro; Carlos A. Steil (Orgs.). Globalização e religião. Petrópolis: Vozes, 1997. p. 43-62.

VELHO, Otávio. Globalização: objeto, perspectiva, horizonte. In: Cândido Mendes; Luiz Eduardo Soares (Orgs.). Pluralismo cultural, identidade e globalização. Rio de Janeiro: Unesco, 2001, p. 103-111.

Autor correspondente:

Airton Luiz Jungblut

Av. Ipiranga, 6681, pr. 5 - Partenon

90619-900 Porto Alegre, RS, Brasil

Recebido em: 3 fev. 2014

Aprovado em: 26 jun. 2014 